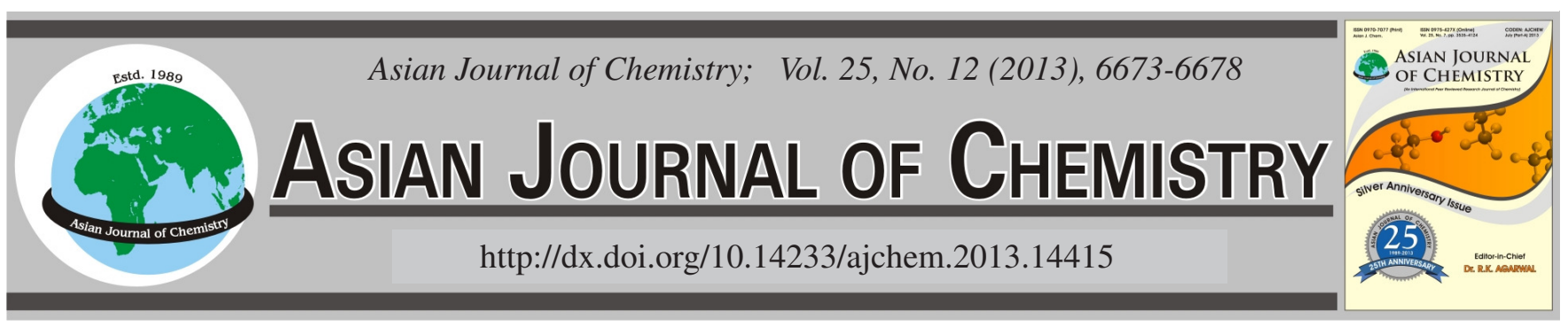

\title{
Preparation of Pyrrole-Thiophene Conductive Polymeric Composite on Cotton Fabric
}

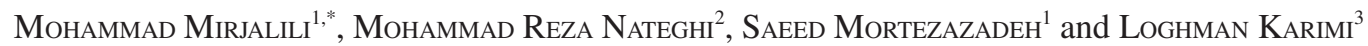

\author{
${ }^{1}$ Department of Textile Engineering, Yazd Branch, Islamic Azad University, Yazd, Iran \\ ${ }^{2}$ Department of Chemistry, Yazd Branch, Islamic Azad University, Yazd, Iran \\ ${ }^{3}$ Young Researchers and Elites Club, Science and Research Branch, Islamic Azad University, Tehran, Iran
}

*Corresponding author: E-mail: mir_textile@yahoo.com

(Received: 8 August 2012;

Accepted: 27 May 2013)

AJC-13546

\begin{abstract}
Coating conventional textile goods with conductive polymer is considered a replacement method for producing conductive goods and layers. In this procedure, polymerization is done in surface of fiber and the surface fiber coated by conductive co-polymer. In this paper, we aim to study the possibility of coating the surface cotton fabric by pyrrole-thiophene composite. In this regard, the polymerization conditions such as time, temperature and ultrasonic effect were examined. In order to compare the conductivity of the samples coated with conductive composites, the cotton samples were also coated with carbon nanotubes and carbon nanotubes-pyrrole composite. To express the conductivity properties of samples, surface resistance of samples in $\Omega / \mathrm{cm}$ was measured according to standard method AATCC 76-1995. The wear resistance and washing fastness of samples were also examined.
\end{abstract}

Key Words: Pyrrole, Thiophene, Composite, Conductive polymers.

\section{INTRODUCTION}

Electrically conductive textiles have received considerable attention due to its possible applications in the areas of electromagnetic shielding, chemical sensors and heating fabrics ${ }^{1-3}$. A new approach to highly conductive textile materials is the use of intrinsically conductive organic polymers ${ }^{4,5}$. The conductive polymers are based on conjugated electron structure, first created in the early 1980's with poly acetylene, a nonprocessable oxygen-sensitive polymer ${ }^{6}$. Today, the inherently conductive polymers such as poly aniline, polypyrrole, polythiophene and poly(per-naphthalene) can be processed and are being used in industrial applications. However, typically the conductive polymer materials are semiconductors. A common approach is to apply dispersions or powders of fully prepared conductive polymers as coating. These approaches usually result in rather low conducting materials. An interesting alternative is to create the conductive polymers by the polymerization of monomers on the textile. Methods for in situ polymerization (by oxidation) are well known for polypyrrole and poly aniline $\mathrm{e}^{7-9}$.

Polypyrrole cannot be directly processed due to its intrinsically poor mechanical properties. Therefore, it is generally used for coating other materials. Polypyrrole-coated fabrics have good electrical conductivity, thermal properties and flexibility suitable for a number of applications ${ }^{10}$. In addition, deposition of thin layers of conductive polymers on the fiber surface of fabrics or yarns does significantly change the mechanical properties of the original material; rather, sometimes it improves these properties. Recent publications on conductive polypyrrole coated yarns and fabrics employ the solution and vapour-phase chemical polymerization methods ${ }^{11-14}$.

Although, coating of textile fibers have been reported by poly thiophene and polypyrrole, these reports are limited to possible coating and reporting of results and also the investigations of coating conditions and the investigations to the fiber coated by pyrrole-thiophene had little attention. In this study, we have investigated the coating conditions, electrical properties and stability of the electrical resistance of the cotton textile coated with pyrrole-thiophene polymeric composite.

\section{EXPERIMENTAL}

The plain weave $100 \%$ cotton fabric was used with the fabric weight of $150 \mathrm{~g} / \mathrm{m}^{2}$. The solution of the pyrrole and the thiophene monomers were purchased from Merck. The CNT used in this investigation are multiwalled carbon nanotubes (MWNT) NC7000 (Nanocyl S.A., Sambreville, Belgium) characterized according to the supplier by an average diameter of 10 $\mathrm{nm}$, a length of 0.1 up to $10 \mu \mathrm{m}$, a carbon purity of $90 \%$ and a surface area of $250-300 \mathrm{~m}^{2} / \mathrm{g}$. The acetonitrile as solvent and iron(III) chloride as oxidizing agent from Merck were prepared.

Preparation of cotton fabrics: The non-cellulosic impurities include pectin (0.4-1.2\%), waxes (0.4-1.2\%), proteins (1.0- 
$1.9 \%)$, ashes (0.7-1.6\%) and other miscellaneous compounds. It is now widely accepted that pectin and the distribution of wax contents are responsible for the non-wetting behaviour of cotton against water. The removal of pectin and waxes from the surface of a cotton fiber will improve its bleachability and dyeability. Cotton samples $(4 \mathrm{~g})$ were scoured in a bath with $2 \mathrm{~g} / \mathrm{L} \mathrm{NaOH}, 5 \mathrm{~g} / \mathrm{L} \mathrm{Na}_{2} \mathrm{CO}_{3}$ and $3 \mathrm{~g} / \mathrm{L}$ nonionic detergent with a liquid ratio of $50: 1$ at $98-100^{\circ} \mathrm{C}$ for $1 \mathrm{~h}$, followed by rinsing with distilled water and then dried at room temperature. Then, the scoured samples were bleached in a solution containing 2 $\mathrm{g} / \mathrm{L} \mathrm{NaOH}, 10 \mathrm{~mL} \mathrm{H}_{2} \mathrm{O}_{2}$ and $1 \mathrm{~mL}$ sodium silicate with a liquidto-fabric ratio of $30: 1$ at $98-100{ }^{\circ} \mathrm{C}$ for $1 \mathrm{~h}$, followed by neutralizing with $0.5 \%$ solution of acetic acid for $5 \mathrm{~min}$ and finally, samples were rinsed with distilled water and dried in an oven preheated in $120^{\circ} \mathrm{C}$ for $1 \mathrm{~h}$.

Coating of the prepared cotton fabrics with polymeric solution: There are three general methods for the oxidative polymerization of fabric; (a) Application of the oxidant to the textile followed by adding the monomer (b) Application of the monomer followed by oxidizing agent and (c) Application of a polymerizable mixture of monomer and oxidant.

For the polymerization of thiophene and pyrrole monomers on the surface samples, we examined each of the three methods, thiophene polymer were chemically produced using oxidant iron(III) chloride.

Thus, in a $250 \mathrm{~mL}$ Erlenmeyer, additional amounts of $16.12 \mathrm{~g}$ of $\mathrm{FeCl}_{3}$ with a volume of acetonitrile were dissolved, next, cotton goods were added to this solution and then, 5.95 $\mathrm{mL}$ of thiophene monomer was added to this mixture. Finally, it was filled with acetonitrile. Over time, in this solution, particles will begin to emerge from dimers and trimer's thiophene and the colour of the solution becomes dark brown. In this stage, $1 \mathrm{~mL}$ of pyrrole monomer is added to the solution. Thus, thiophene and pyrrole are simultaneously polymerized on the fabrics. The second method is the same except that, first, thiophene monomer is added then, $\mathrm{FeCl}_{3}$ is added for the oxidation of monomer and polymerization. In the third method, thiophene monomer and $\mathrm{FeCl}_{3}$ are simultaneously added to the Erlenmeyer containing the sample and acetonitrile in order for polymerization.

Effects of temperature (ambient temperature and $5^{\circ} \mathrm{C}$ ), polymerization time (2, 3, 5, 7 and 10 days) and ultrasound were investigated.

Padding of the cotton fabrics in carbon nanotubes dispersion: For the preparation of the carbon nanotubes dispersions, various amounts $(0.1,0.2,0.3$ and $0.4 \mathrm{~g})$ of carbon nanotubes were added to $100 \mathrm{~mL}$ of distilled water. Next, cotton samples were immersed into the solution and were taken out after $10 \mathrm{~min}$. Samples were dried in an oven at $100^{\circ} \mathrm{C}$ and again the samples were immersed into the solution. Due to the porous structure of cotton fibers and the swelling of the cotton fibers in the solution, carbon nanotubes were absorbed by the fibers. This procedure is repeated several times to increase the amount of carbon nanotubes on the cotton goods. These procedures were carried out under two conditions i.e., normal and ultrasound.

In order to investigate the effects of coating conductive polymer and carbon nanotubes on the samples, the sample was padded in carbon nanotube solution with the above method (ultrasonic) and then dried. Thereafter, the dried sample was placed in pyrrole monomer solution as listed in the above steps, pyrrole was polymerized on the fabric. This first layer of carbon nanotubes was embedded on the sample surface and then obtained conductive fabric by polymerization of pyrrole on the surface of the coated fabric.

Surface resistance measurements on conducting textiles: In the case of coated fabrics, surface resistivity in $\Omega / \mathrm{sq}$ (ohms per square) is used to express the electrical property, rather than festivity in $\Omega / \mathrm{m}$. The surface resistivity of the conducting fabrics was measured according to AATCC test method 761995 using a 34401 Amultimeter (Agilent Technologies) after conditioning in a standard atmosphere $\left(20^{\circ} \mathrm{C}, 65 \% \mathrm{RH}\right)$. This method involves two rectangular copper electrodes $(20 \mathrm{~mm} \times$ $30 \mathrm{~mm}$ ) being pressed onto the fabric surface with a $10 \mathrm{~N}$ pressure (Fig. 1). The measurement device was placed on the flat fabric and a relaxation time of $120 \mathrm{~s}$ prior to each resistance measurement was allowed. This was repeated at least ten times for each sample. Besides measuring the electrical

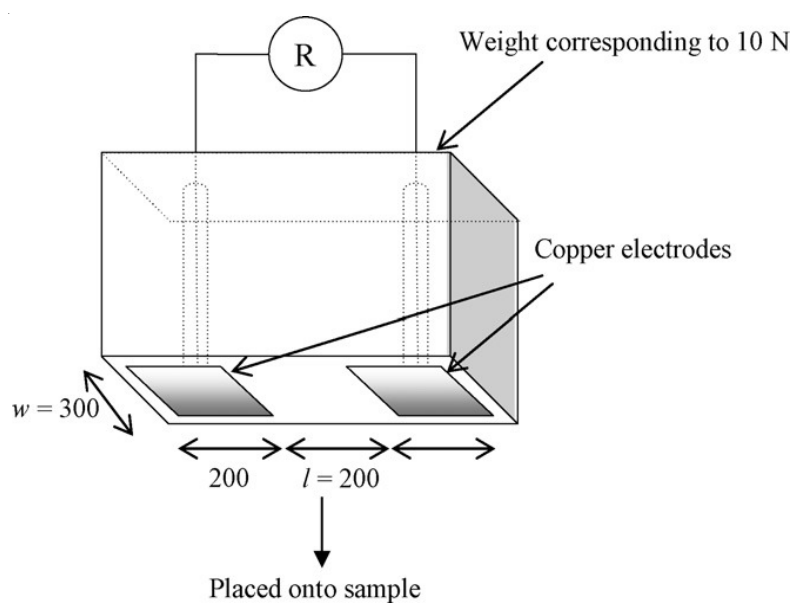

Fig. 1. Schematic of surface resistivity measurement device of textiles according to AATCC 76-1995

properties of samples, another method was also used to measure the voltage-current specifications. In this method, the electrical properties of the samples are described by the current-voltage curve. According to this method, the electrical current has to be measured across the connection base (the distance between the base and $30 \mathrm{~mm}$ ) on textiles. The only difference with the standard method is the kind of bars, in this case, the bars are made of stainless steel, having a height of $40 \mathrm{~mm}$, but in the standard method, the bars are made of copper. Constant voltage was applied to the contacting bars with either a DC-voltage supply (TK3, Gossen) or a $30 \mathrm{~V}$ AC-voltage supply (Leyboldt Didaktik, Hürth). The resulting current was measured with a conventional multimeter with a range up to $400 \mathrm{~mA}$ (M-3270D, Metex) (Fig. 2).

Scanning electron microscopy analyses: SEM characterization was performed using a LEO Stereoscan model 440 microscope at an acceleration voltage of $20 \mathrm{kV}$ and $15 \mathrm{~mm}$ working distance. Samples were mounted onto an aluminum specimen stubs by means of double-sided adhesive tape and sputter-coated with a thin gold layer under rarefied Argon atmosphere, using a BAL-TEC MED 020 Coating System, with a current of $30 \mathrm{~mA}$ for $180 \mathrm{~s}$. 


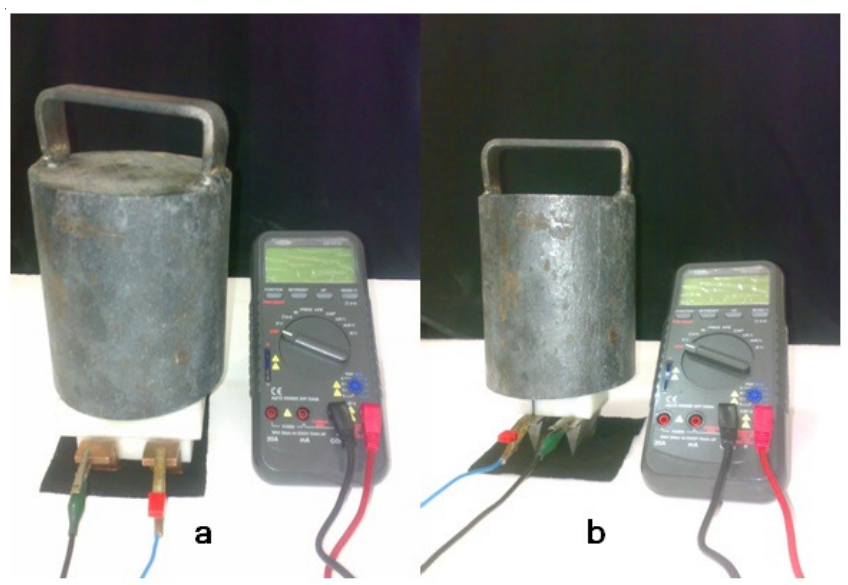

Fig. 2. Equipments for the measurement a) surface resistivity of textiles according to AATCC 76-1995, b) current-voltage curve. The fabric samples are contacted by means of two contact bars of $4 \mathrm{~cm}$ length and distance of $3 \mathrm{~cm}$, pressed onto the fabric with $10 \mathrm{~kg}$

Changes in electrical properties caused by washing and the wear: In order to assess the stability of electrical properties caused by wear and washing, wear resistance and washing fastness were evaluated according to ISO-105-C01 1992 (E) and ISO- 105-X12 1993 (E) test methods, respectively.

\section{RESULTS AND DISCUSSION}

Effect of polymerization time in normal conditions: Since the thiophene oxidation potential is lower than that of pyrrole, Thiophene was first polymerized and then the pyrrole monomer was added to it. For this purpose, after $3 \mathrm{~h}$ adding thiophene and appearing of dimers and trimers thiophene particles, pyrrole is added to solution polymerization, that copolymerization thiophene and pyrrole simultaneously be done. To assess polymer formation and the complete degradation time of the polymer, the surface resistance of the samples was measured after 1, 2, 3 and 10 days. The results are shown in Fig. 3 and also in Fig. 4. As evident in Fig. 3, in the $1^{\text {st }}$ day, the polymer was formed in a non-uniform manner on the fabric surface. However on the $2^{\text {nd }}$ day, the polymerization was more uniform. In the $3^{\text {rd }}$ and $4^{\text {th }}$ day, polymerization was completed and the resistance was the almost the same until the $6^{\text {th }}$ day. After the $7^{\text {th }}$ day, the resistance level rose and the reason for this is related to the degradation of the polymer. After recording the resistance value on the $10^{\text {th }}$ day, it was found that the polymer was completely degraded. With the measurement method involving stainless steel electrodes, the surface resistance measured was $8.75 \mathrm{~K} \Omega / \mathrm{sq}$ in the $6^{\text {th }}$ day. It can be seen that with increasing applied voltage, the current through the sample increases uniformly (Fig. 4).

Effect of polymerization temperature in normal conditions $\left(5^{\circ} \mathbf{C}\right)$ : According to previous studies, if polymerization is conducted at lower temperatures, the polymer formed on the surface will be more uniform and stable. To test this hypothesis, we investigated the effect that temperature and ambience has on polymerization. For the study, we kept the temperature at $5{ }^{\circ} \mathrm{C}$. At $5{ }^{\circ} \mathrm{C}$, thiophene particles were formed within $12 \mathrm{~h}$ and then pyrrole was added. At this temperature, by the sixth day, the lowest level of resistance was observed
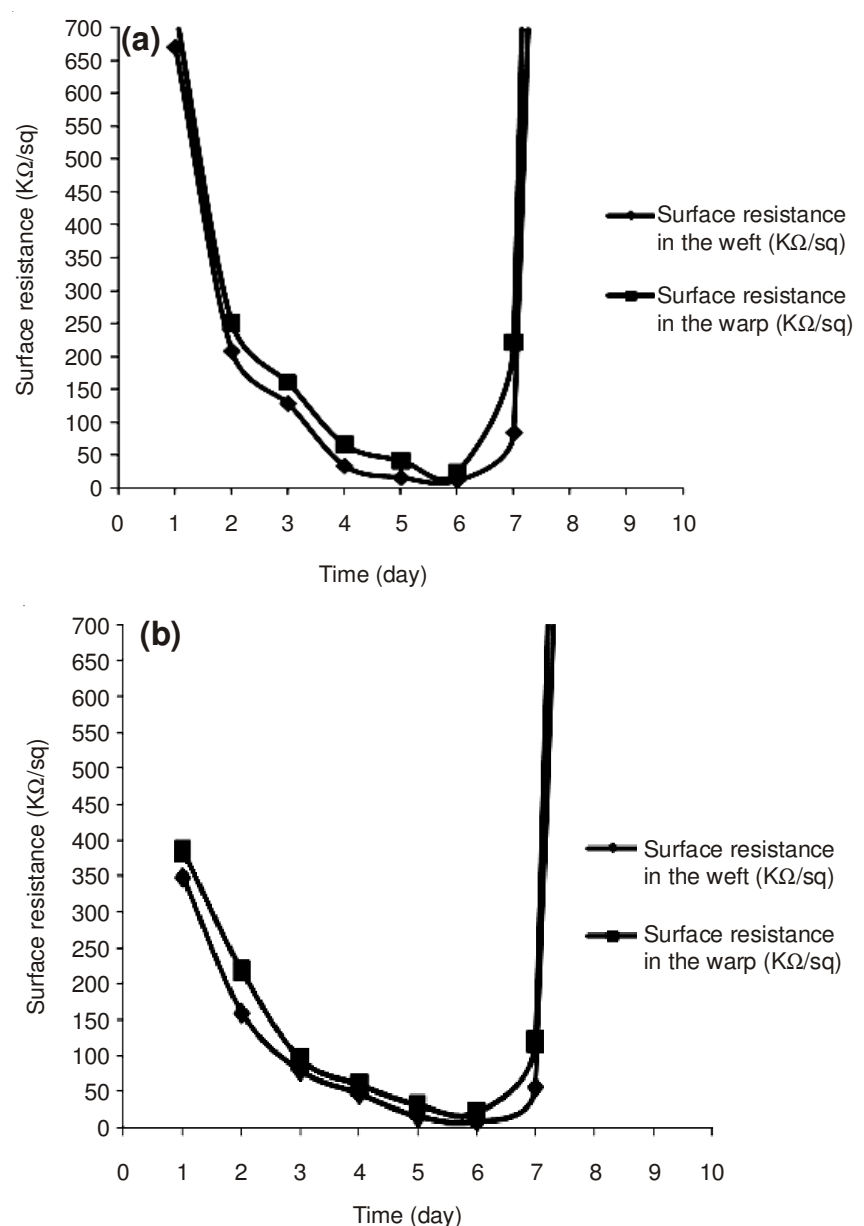

Fig. 3. Changes of surface resistance in term time in ambient temperature according to: a) standard AATCC 76-1995, b) using steel electrode
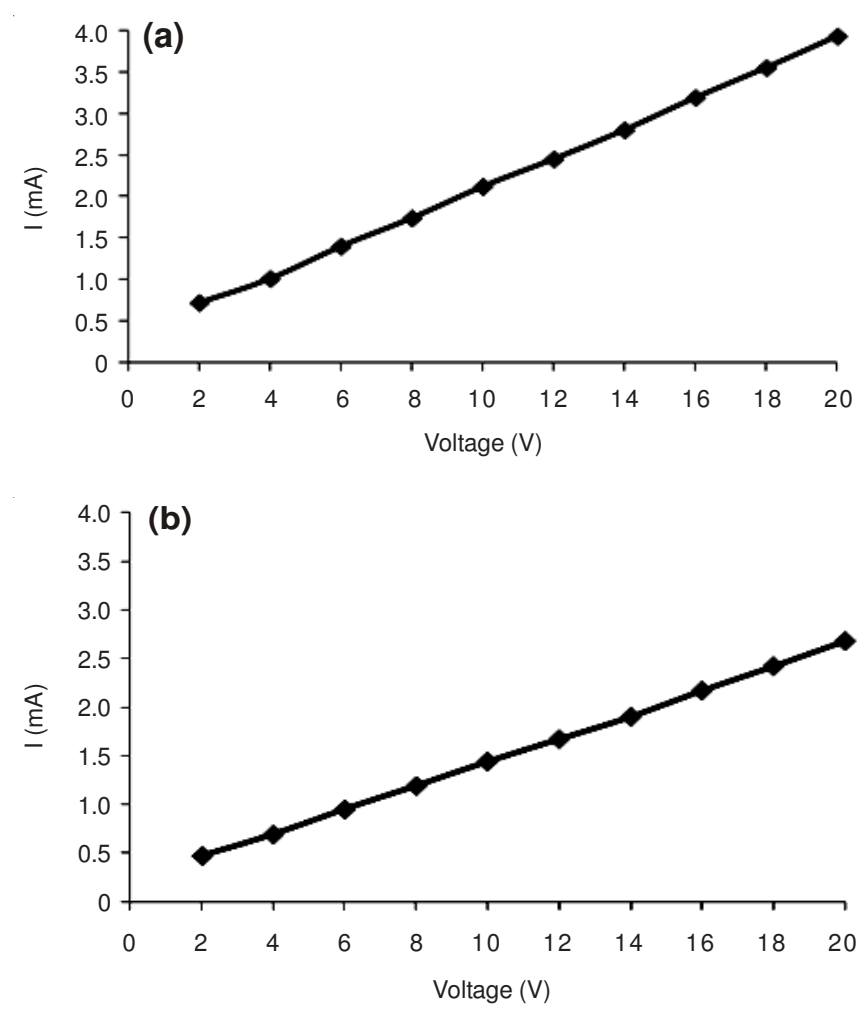

Fig. 4. Current-voltage curves of the samples coated with a mixture pyrrole/ thiophene according to: a) standard AATCC 76-1995, b) using steel electrodes 
up to this time the resistance level was declining. It was again observed on the $10^{\text {th }}$ day that the polymer was completely degraded. It must be noted that in conventional polymerization, polymer particles are attached together and non-uniformly placed on the fabric surface. These particles are easily separated from the surface because the fabric surface has become falt. The results of the surface resistance and current-voltage measurements based on AATCC 76-1995 standard method is shown in Fig. 5. In addition, the results of the current-voltage, measured using stainless steel electrodes, are shown in Fig. 6. The surface resistance measured with this method was 17.43 $\mathrm{K} \Omega / \mathrm{sq}$ on the $6^{\text {th }}$ day.
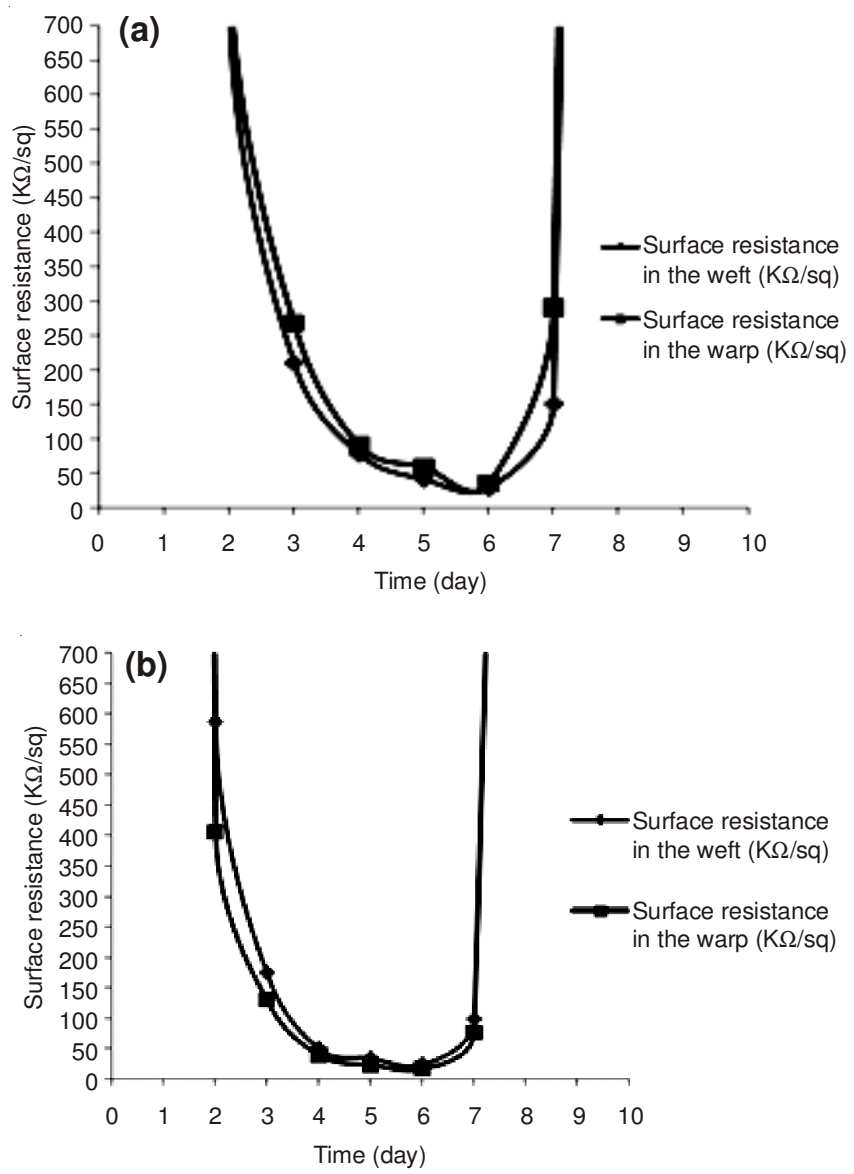

Fig. 5. Changes of surface resistance in $5{ }^{\circ} \mathrm{C}$ according to: a) standard AATCC 76-1995, b) using steel electrode

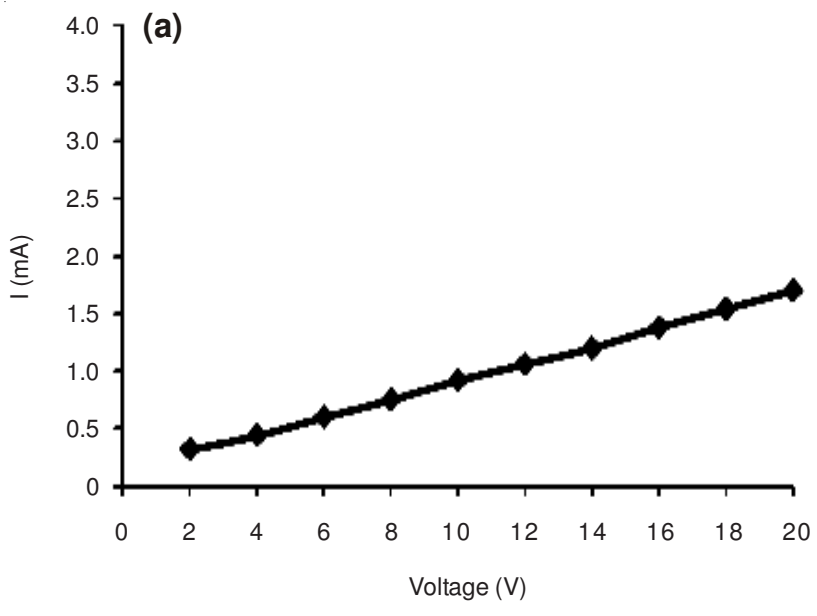

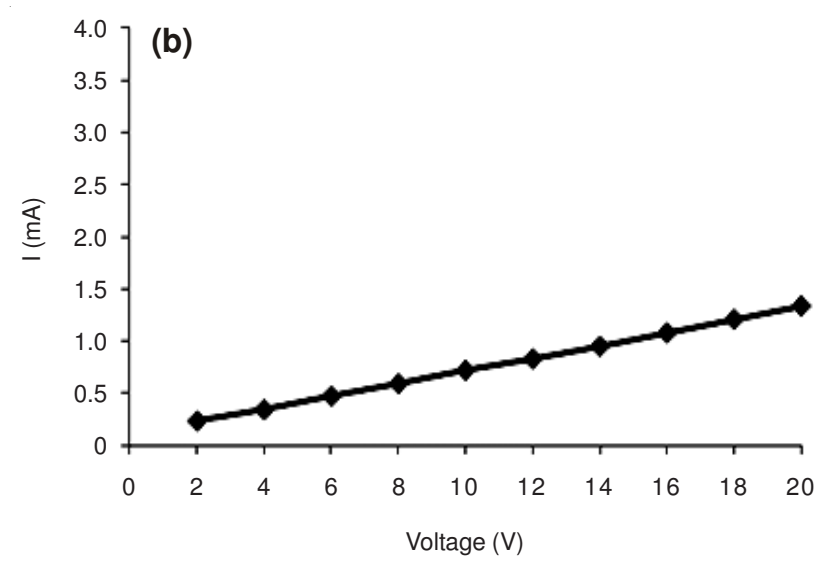

Fig. 6. Current -voltage curves of the samples coated with a mixture pyrrole/ thiophene in $5^{\circ} \mathrm{C}$ according to: a) standard AATCC 76-1995, b) using steel electrodes

Effect of ultrasonic wave: The effect of ultrasound on polymerization time was investigated. In this experiment, particles of polymer began to emerge in the first half of the experiment and after adding pyrrole monomer, the surface resistance of the samples was measured within a range $2-8 \mathrm{~h}$. The results of ultrasound are shown in Figs. 7 and 8. It can be seen from the results that polymerization was done in less time and polymeric layer formed uniformly on the fabric surface. According to the results obtained and among the conditions listed above, the best mode for polymerization was chosen under ultrasound condition, in ambient temperature and a time of $6 \mathrm{~h}$.

Conductivity of padded fabric in the solution of carbon nanotubes: The effects of different amounts of carbon nanotubes, $0.1,0.2,0.3$ and $0.4 \mathrm{~g}$ on the surface resistance of fabrics in conventional and ultrasonic conditions were evaluated. In comparison with normal conditions, there are more distributed and uniform coating of nanoparticles on the fabric surface under ultrasound waves. It was observed that the lowest surface resistance relates to the padded sample in solution of $0.3 \mathrm{~g} \mathrm{CNT}$. It can be stated from the results that the surface of the sample was saturated with $0.3 \mathrm{~g}$ of carbon nanotubes and much of it remains in the solution, or can easily be separated from the surface by washing (Tables 1 and 2). Also, the value of the CNT-pyrrole coated samples surface resistance was $19.18 \mathrm{~K} \Omega / \mathrm{sq}$.

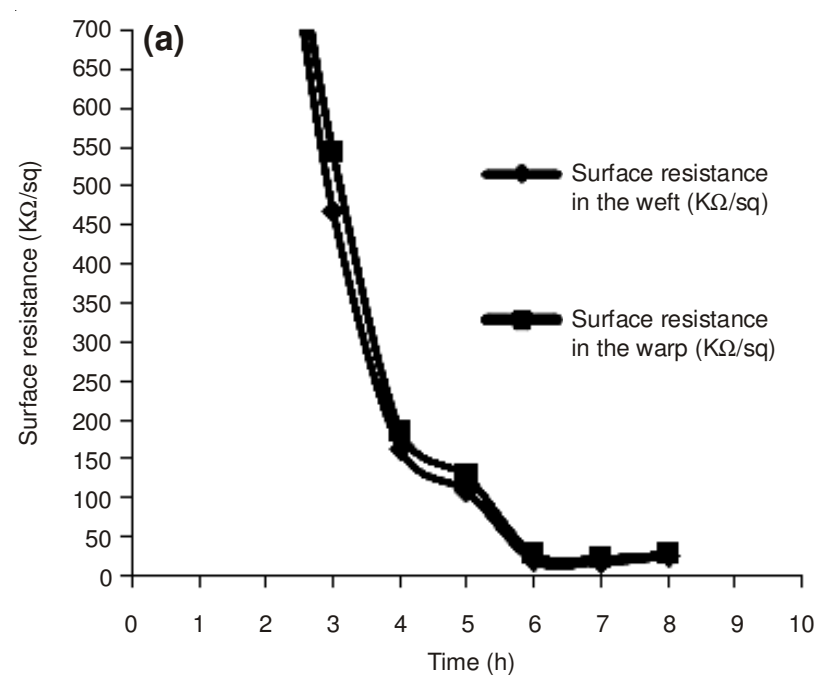




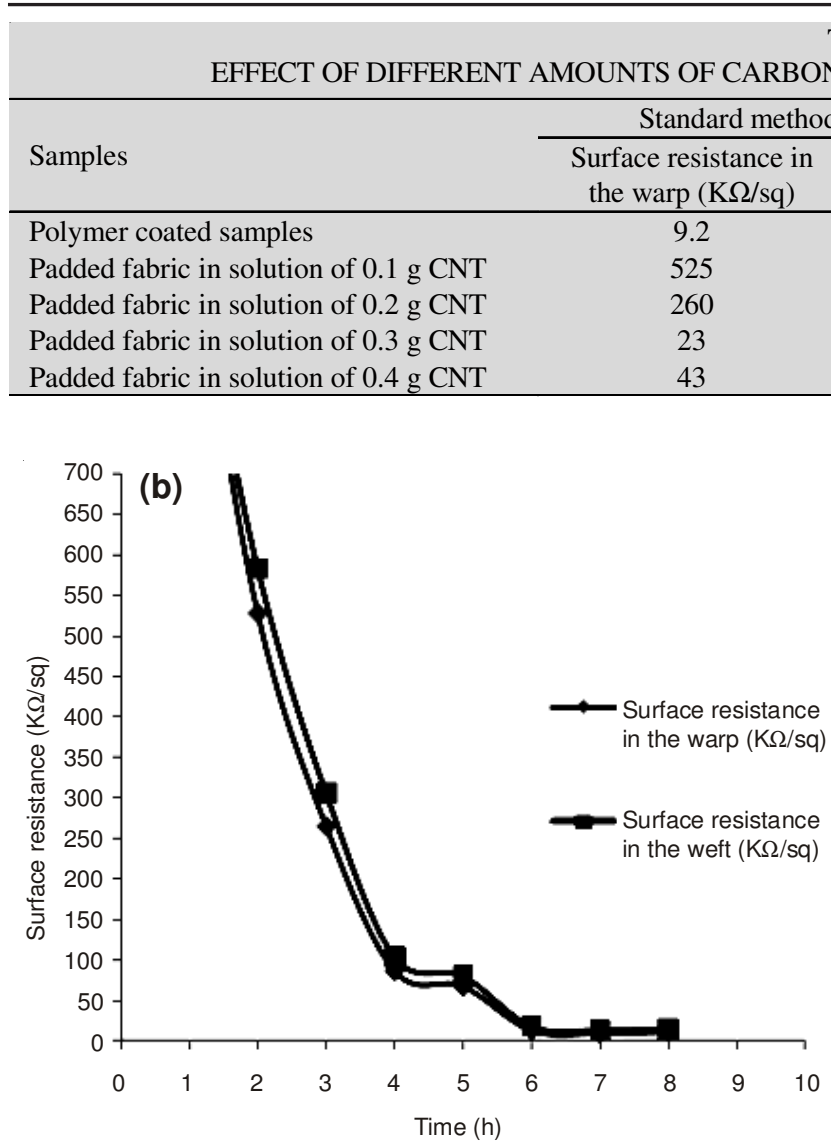

Fig. 7. Changes of surface resistance in ultrasound conditions according to: a) standard AATCC 76-1995, b) using steel electrode
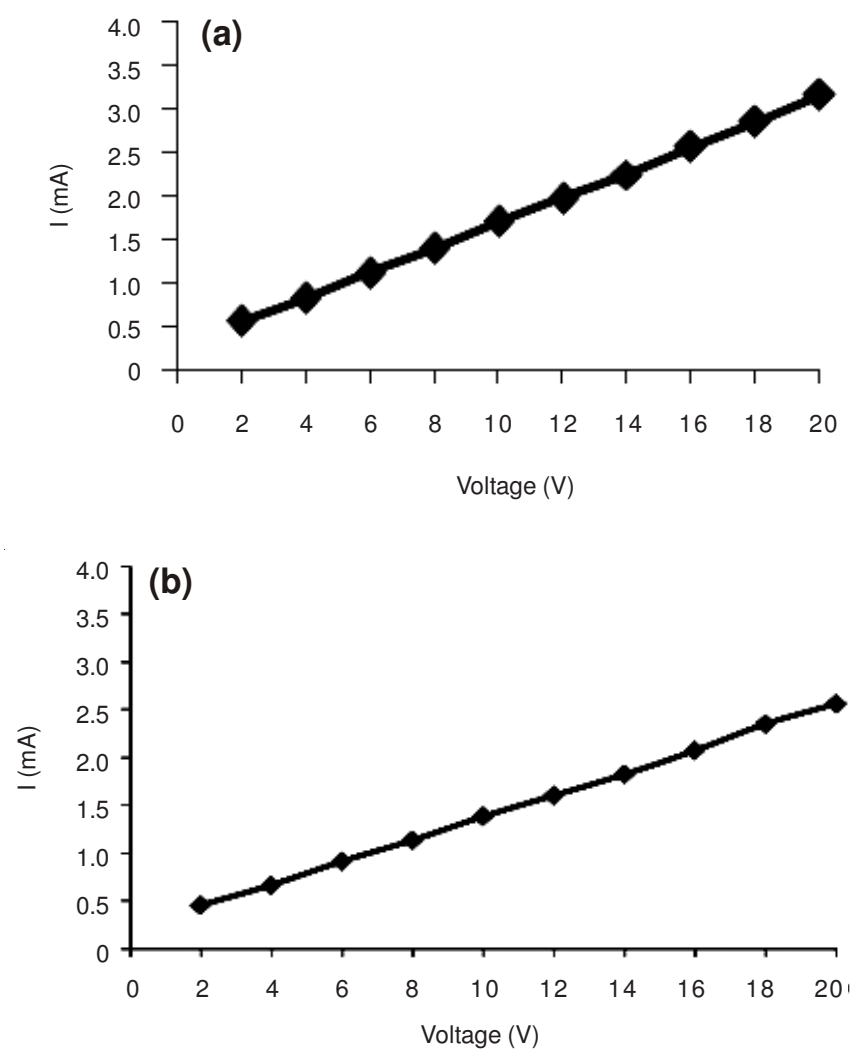

Fig. 8. Current-voltage curves of the samples coated with a mixture pyrrole/ thiophene in ultrasound conditions according to: a) standard AATCC 76-1995, b) using steel electrodes

\section{TABLE-1}

NANOTUBE ON CONDUCTIVITY OF PADDED FABRIC

\begin{tabular}{c|cc}
\hline $\begin{array}{c}\text { Surface resistance in } \\
\text { the weft }(\mathrm{K} \Omega / \mathrm{sq})\end{array}$ & $\begin{array}{c}\text { Surface resistance in } \\
\text { the warp }(\mathrm{K} \Omega / \mathrm{sq})\end{array}$ & $\begin{array}{c}\text { Surface resistance in } \\
\text { the weft }(\mathrm{K} \Omega / \mathrm{sq})\end{array}$ \\
\hline 18.6 & 9.2 & 18.6 \\
608 & 276.4 & 324.8 \\
345 & 145.7 & 182.3 \\
32 & 12.6 & 17.4 \\
48 & 27 & 30.2 \\
\hline
\end{tabular}

TABLE-2

RESULTS OF THE CURRENT- VOLTAGE OF PADDED SAMPLE IN A SOLUTION 0.3 g CNT (STANDARD AATCC 76-1995)

\begin{tabular}{ccc}
\hline $\begin{array}{c}\text { Applied } \\
\text { voltage }(\mathrm{V})\end{array}$ & $\begin{array}{c}\text { Current }(\mathrm{mA}) \text { using a } \\
\text { copper electrode }\end{array}$ & $\begin{array}{c}\text { Current }(\mathrm{mA}) \text { using a } \\
\text { steel electrode }\end{array}$ \\
\hline 2 & 0.37 & 0.3 \\
4 & 0.53 & 0.42 \\
6 & 0.73 & 0.58 \\
8 & 0.92 & 0.72 \\
1 & 1.12 & 0.90 \\
12 & 1.29 & 1.02 \\
14 & 1.47 & 1.18 \\
16 & 1.68 & 1.34 \\
18 & 1.91 & 1.50 \\
20 & 2.07 & 1.67 \\
\hline
\end{tabular}

Surface characteristics coated fabrics: To investigate the changes in surface morphology of the coated fabrics, SEM technique was employed. The results are shown in Fig. 9. In the Fig. 9a, the sample surface of the raw fabric is shown. It can be seen that the surface is free of the polymer particles. In the Fig. $9 b, c, d$ and e, it can be observed that the surface of the samples was covered with particles of polymer and carbon nanotubes.
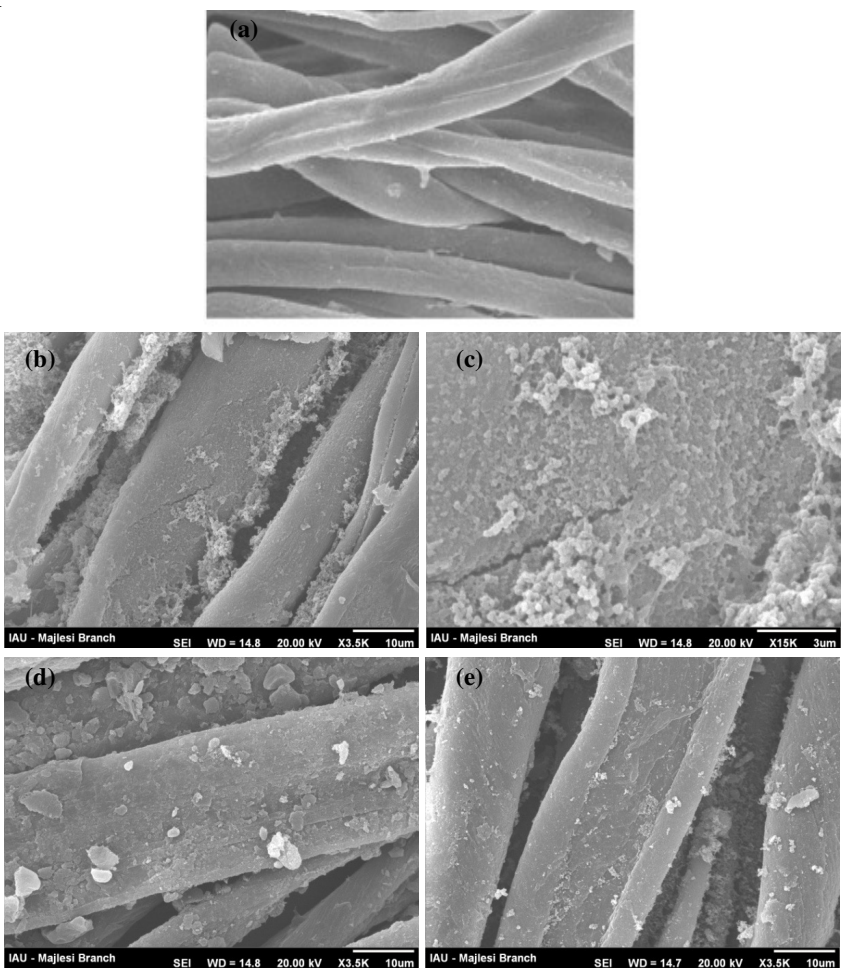

Fig. 9. SEM images of cotton samples, a) Rinsed, b and c) Coated with a pyrrole-thiophene, d) Coated with CNT and e) Coated with CNTpyrrole 
TABLE-3

RESULTS OF THE WEAR RESISTANCE AND WASHING FASTNESS OF THE PREPARED SAMPLES

\begin{tabular}{|c|c|c|c|c|c|c|c|c|c|c|}
\hline & \multicolumn{6}{|c|}{ Surface resistance after abrasion $(\mathrm{K} \Omega / \mathrm{sq})$} & \multicolumn{4}{|c|}{ Surface resistance after washing $(\mathrm{K} \Omega / \mathrm{sq})$} \\
\hline Treatment cycle & - & 10 & 50 & 100 & 200 & 500 & 5 & 10 & 15 & 20 \\
\hline Coated with a pyrrole-thiophene & 19.2 & 22 & 26 & 31 & 46 & 67 & 26 & 31 & 45 & 48 \\
\hline Coated with CNT & 23 & 27 & 35 & 43 & 74 & 125 & 35 & 42.4 & 48.6 & 78.9 \\
\hline Coated with CNT-pyrrole & 19.18 & 24 & 32 & 38 & 61 & 85 & 37 & 44 & 51 & 58 \\
\hline
\end{tabular}

Wear resistance and washing fastness of coated samples: To study the wear resistance of pyrrole/thiophene polymeric layer and carbon nanotubes, a sample was prepared and was worn. Then conductivity of the sample was analyzed. The results are shown in Table-3. It was observed that washing stability of the samples is too low because the surface resistance of the samples greatly increases only by one or two times of washing with nonionic detergent, but conductivity of the samples after the abrasion is reduced only slightly. Good wear stability can be due to deep coating and penetration of the polymer into the fabric.

\section{Conclusion}

In this paper, different copolymerization conditions of the pyrrole-thiophene, electrical properties and the stability of the electrical resistance of the cotton textile coated with pyrrolethiophene co-polymer were investigated. Using ultrasonic bath results in a significant reduction in the polymerization time; it also gives a homogeneous polymer solution and causes the polymerization to be carried out smoothly. It must be noted that the polymer solution obtained at low temperatures $\left(5^{\circ} \mathrm{C}\right)$ is more uniform and stable than the polymer achieved in ambient conditions. Moreover, polymerization time has been longer than 6 days; also, the polymer has been degraded. It can be stated that in normal conditions, before the fourth day, the polymer coating is not fully formed. Washing fastness of the samples in standard condition is too low because the surface resistance of the samples significantly increases only by one or two times of washing with non-ionic detergent. Finally, it must be noted that the use of acetonitrile as solvent instead of water leads to the formation of uniform polymer on the surface of the sample.

\section{REFERENCES}

1. T. Taka, Synth. Met., 41, 1177 (1991).

2. T. Makela, H. Isotalo, J. Sten and A. Hujanen, Synth. Met., 101, 707 (1999).

3. J.D. Strenger-Smith, Prog. Polym. Sci., 23, 57 (1998).

4. S.J. Pomfret, P.N. Adams, A.P. Montman and N.P. Comfort, Synth. Met., 101, 724 (1999).

5. A. Andreatta, Y. Cao, J.C. Chiang, A.J. Heeger and P. Smith, Synth. Met., 26, 383 (1988).

6. T. Ito, H. Shirakawa and S. Keda, J. Polym. Sci. Polym. Chem., 1, 11 (1974).

7. K.W. Oh and S.H. Kim, J. Appl. Polym. Sci., 74, 2094 (1999).

8. R. Anbarsan, J. Jayaseharan, M. Sudha, J.L. Devi, P.V. Nirmala and A.J. Gopalan, J. Appl. Polym. Sci., 81, 468 (2001).

9. H.H. Li, C.Q. Shi, W. Ye, C. Li and Y.Q. Liang, J. Appl. Polym. Sci., 64, 2149 (1997).

10. J.P. Boutrois, R. Jolly and C. Petrescu, Synth. Met., 85, 1405 (1997).

11. L. Dall'Acqua, C. Tonin, R. Peila, F. Ferrero and M. Catellani, Synth. Met., 146, 213 (2004).

12. S. Sh. Najar, A. Kaynak and R.C. Foitzik, Synth. Met., 157, 1 (2007).

13. A. Varesano, L. Dall'Acqua and C. Tonin, Polym. Degrad. Stab., 89, 125 (2005)

14. S. Garg, C. Hurren and A. Kaynak, Synth. Met., 157, 41 (2007). 